\title{
APRENDIZAGEM BASEADA EM PROJETOS: CONTRIBUIÇÕES DAS TECNOLOGIAS DIGITAIS
}

\author{
Diego de Oliveira Silva* \\ Juscileide Braga de Castro ${ }^{* *}$ \\ Gilvandenys Leite Sales ${ }^{* * *}$
}

\begin{abstract}
Resumo: A inserção de recursos tecnológicos em sala de aula traz novas possibilidades e desafios para a prática pedagógica. No entanto é preciso que haja um planejamento que contemple as peculiaridades destas novas ferramentas, permitindo que professores e alunos possam usufruir de suas vantagens. Dessa forma, este trabalho se propõe a apresentar intervenções baseadas na Aprendizagem Baseada em Projetos (ABP) realizadas em uma escola municipal de Fortaleza, bem como analisar as contribuições das tecnologias digitais neste tipo de metodologia. Para isso são detalhados os projetos "Um Mundo de Informações" e "Pensar, Conectar e Fazer" aplicados, respectivamente, em turmas de $5^{\circ}$ e $6^{\circ}$ anos do Ensino Fundamental. Além disso, é realizada uma avaliação das ferramentas digitais utilizadas nestas atividades. Concluiu-se que a utilização destas ferramentas influenciou de maneira positiva na aplicação dos projetos, além de permitir a integração do conhecimento em nível interdisciplinar e na criação de produtos educacionais.
\end{abstract}

Palavras-chave: Aprendizagem baseada em projetos. Tecnologias digitais. Metodologia Ativa. Interdisciplinaridade.

\section{Introdução}

A evolução das tecnologias digitais de informação e comunicação (TDIC) tem oportunizado mudanças na educação ao propiciarem novas formas de construção do conhecimento. No entanto é necessário ressaltar que a utilização de novas tecnologias em sala de aula deve estar atrelada a um planejamento prévio, a uma metodologia que possa integrar suas potencialidades ao que se pretende transmitir aos alunos, sob o risco de se criar um obstáculo epistemológico, dissociando a tecnologia e o aprendizado aos olhos dos discentes (MORAN; MASETTO; BEHRENS, 2006).

Para Hansen e Deffacci (2015) o computador pode se apresentar de diferentes maneiras no contexto escolar. Quando o mesmo é utilizado simplesmente para transmitir informações, como uma máquina de ensinar, perpetua-se o método de ensino tradicional em

\footnotetext{
* Mestrando do Programa de Pós-Graduação em Ensino de Ciências e Matemática (PGECM) do Instituto Federal de Educação, Ciência e Tecnologia do Ceará (IFCE).

** Doutora em Educação pela Universidade Federal do Ceará (UFC). Professora Adjunta da UFC, vinculada a Faculdade de Educação/FACED e ao Departamento de Teoria e Prática do Ensino.

*** Doutor em Engenharia de Teleinformática pela Universidade Federal do Ceará (UFC). Professor Titular de Física do Instituto Federal de Educação, Ciência e Tecnologia do Ceará (IFCE).
} 
que o aluno é apenas um receptor passivo dos conteúdos apresentados. No entanto, quando o computador é utilizado como uma ferramenta da qual o aluno se apropria na construção do próprio conhecimento, reconhece-se a presença de uma metodologia construtivista na prática pedagógica.

No entanto, para Buckingham (2009) existem poucas evidências de que a utilização das TDIC por si só leve a uma evolução da aprendizagem dos estudantes em sala de aula. Isto, pois, enquanto em seu cotidiano o aluno está inserido em um ambiente saturado de informações, o uso das tecnologias digitais ainda é relativamente pouco visto dentro de ambientes formais de ensino. A introdução da informática em sala de aula, além de trazer novas possibilidades para a prática do ensino, pode contribuir para a democratização das dinâmicas entre professores e alunos, conferindo um caráter colaborativo à aprendizagem (MISKULIN et al., 2006).

Ao analisar um repositório de recursos digitais para o ensino de Matemática, Batista (2004) pôde constatar, quanto à eficácia destas ferramentas, a necessidade de que o professor faça uso de metodologias capazes de integrar a tecnologia ao contexto do aluno. Além disso, Sahin e Thompson (2006) afirmam que um dos motivos que levam educadores a não fazerem uso de computadores em sala de aula é a exigência de que os professores mudem seus métodos tradicionais de ensino, sua postura em sala e habilidades mentais. Assim sendo, o uso de metodologias ativas de aprendizagem se mostra como uma maneira promissora de integrar o uso das TDIC ao contexto escolar.

Metodologias ativas de aprendizagem, na definição de Prince (2004), constituem-se como uma série de ações e técnicas que têm por objetivo engajar os alunos em procedimentos que os levem a uma aprendizagem significativa. Nesse contexto encontra-se a aprendizagem colaborativa, na qual os estudantes trabalham em grupos para alcançarem um objetivo previamente definido (La ROCCA; MARGOTTINI; CAPOBIANCO, 2014).

A pedagogia de projetos e a aprendizagem baseada em projetos são práticas que se enquadram na esfera das metodologias colaborativas. A primeira é mais voltada para o ensino, com uma hierarquia bem definida, onde o professor determina as etapas do processo. Já a segunda tem como foco a aprendizagem, apresentando uma maior democratização das tomadas de decisão e um professor que assume o papel de colaborador nos procedimentos definidos pelo grupo.

Desta forma, acredita-se que a utilização das tecnologias digitais da informação pode enriquecer a prática pedagógica quando integrada à metodologias ativas de aprendizagem, 
mais especificamente a aprendizagem baseada em projetos. Sendo assim, este artigo tem como objetivos apresentar projetos colaborativos realizados no âmbito da Educação Básica e analisar as contribuições das tecnologias digitais na aprendizagem baseada em projetos.

Na próxima seção discorre-se sobre a metodologia de projetos e como a mesma pode se beneficiar da utilização das tecnologias digitais. Em seguida, são apresentados os procedimentos metodológicos desta pesquisa, uma discussão a respeito dos projetos aplicados para o ensino de Matemática na Educação Básica e como a utilização de ferramentas tecnológicas contribuiu para a realização dos mesmos. Por fim, são apresentados os resultados da pesquisa e possibilidades de futuros estudos.

\section{A Metodologia de projetos e as tecnologias digitais}

O conhecimento de Matemática é necessário para a compreensão plena de uma série de outros assuntos abordados no âmbito escolar. Química, Física e Biologia apresentam conjuntos próprios de representações conceituais e modelos mentais utilizados para descrever os fenômenos e teorias dos quais tratam. Apesar destes campos do conhecimento serem diversos entre si, a linguagem matemática está presente em todos eles, e é o uso adequado desta linguagem que fornece formalismo às suas teorias (GRECA; MOREIRA, 2001).

Não obstante sua importância, a Matemática é uma das matérias com maior nível de rejeição por parte dos alunos. Segundo Tatto e Scapin (2004) dentre as razões que levam os estudantes a preterirem esta matéria estão a pré-concepção de que a Matemática é uma matéria mais difícil que as outras, a falta de uma correlação entre o que é estudado e a vida prática do aluno, o papel de receptor passivo imposto ao estudante durante as aulas e a apatia de certos professores. Sendo assim, é preciso buscar maneiras de modificar este cenário pedagógico, utilizando tecnologias e metodologias que permitam ao aluno enxergar a matéria como parte do seu dia a dia, conectando-se de maneira significativa com a mesma.

A Pedagogia de Projetos (PP) tem como função atrelar o conhecimento científico e teórico à realização de uma prática, algo concreto capaz de estabelecer uma ligação entre o contexto do aluno e a matéria (NOGUEIRA, 2009). Esta metodologia surgiu como proposta pedagógica em 1919, quando as ideias de John Dewey influenciaram William Heard Kilpatrick. A ideia era a de atrelar o aprendizado à resolução de problemas comuns ao cotidiano dos alunos, desatrelando a teoria do contexto estritamente escolar (MENEZES; FARIA, 2003). 
Já a Aprendizagem Baseada em Projetos (ABP) é uma modalidade de aprendizagem colaborativa na qual os alunos formam grupos, aos quais são designadas tarefas de pesquisa ou investigação (KARAHOCA; KARAHOCA; UZUNBOYLUB, 2011). O objetivo deste tipo de metodologia é estimular o pensamento crítico dos estudantes, levando os mesmos a coletar informações, formular e refinar perguntas, fazer predições e compartilhar suas ideias e conclusões com os colegas. Para Boss, Larmer e Mergendoller (2013) a ABP é uma estratégia de ensino que pode aumentar a motivação dos alunos, contribuindo para o desenvolvimento de competências e fomentando um aprendizado centrado na figura do discente.

As duas metodologias apresentam similaridades ao buscar uma aproximação do conhecimento escolar com a prática mediante a resolução de problemas. No entanto a Pedagogia de Projetos tem um caráter mais hierárquico, no qual o professor define o problema e os passos necessários para sua solução. Na Aprendizagem Baseada em Projetos são os alunos, juntamente com o professor, que definem o tema do projeto de maneira cooperativa. Os alunos têm autonomia para decidirem como abordar o problema em questão, com o professor fazendo às vezes de mediador da investigação. Sendo assim, conforme visualizado no Quadro 1, enquanto a Pedagogia de projetos está mais voltada para o ensino, a ABP tem características de projeto de aprendizagem.

Quadro 1: Projetos de Ensino e Projetos de Aprendizagem.

\begin{tabular}{|c|c|c|}
\hline & Projeto de Ensino & Projeto de Aprendizagem \\
\hline $\begin{array}{l}\text { Escolha do tema a ser } \\
\text { investigado }\end{array}$ & $\begin{array}{l}\text { Professores, } \\
\text { coordenação pedagógica }\end{array}$ & $\begin{array}{l}\text { Alunos e professores, individualmente } \\
\text { e, ao mesmo tempo, em cooperação }\end{array}$ \\
\hline Contextos & $\begin{array}{l}\text { Arbitrado por critérios externos e } \\
\text { formais }\end{array}$ & $\begin{array}{l}\text { Realidade da vida do aluno, além do } \\
\text { currículo }\end{array}$ \\
\hline A quem satisfaz & $\begin{array}{l}\text { Arbítrio da sequência de conteúdos } \\
\text { do currículo sequência única e } \\
\text { geral }\end{array}$ & $\begin{array}{l}\text { Curiosidade, desejo, vontade do } \\
\text { aprendiz, não há uma sequência única e } \\
\text { geral }\end{array}$ \\
\hline Decisões & Hierárquicas & Heterárquicas \\
\hline $\begin{array}{l}\text { Definições de regras, } \\
\text { direções e atividades }\end{array}$ & $\begin{array}{l}\text { Impostas pelo sistema, cumpre } \\
\text { determinações sem optar }\end{array}$ & $\begin{array}{l}\text { Elaboradas pelo grupo, consenso entre } \\
\text { alunos e professores. }\end{array}$ \\
\hline Desenvolvimento & $\begin{array}{l}\text { Linear e previsível, do mais fácil } \\
\text { ao mais difícil }\end{array}$ & $\begin{array}{l}\text { Não é linear, nem previsível. } \\
\text { Incompatível com a ideia de caminhar } \\
\text { do mais fácil para o mais difícil }\end{array}$ \\
\hline Pré-requisito & Definido pelo professor & $\begin{array}{l}\text { Definido pelo aluno em função do que } \\
\text { deseja conhecer e do que já sabe }\end{array}$ \\
\hline Paradigma & Transmissão do conhecimento & Construção do conhecimento \\
\hline
\end{tabular}




\begin{tabular}{|l|l|l|}
\hline Professor & Agente & Instigador, orientador, pesquisador \\
\hline Aluno & Receptivo & Agente \\
\hline
\end{tabular}

Fonte: Adaptado de Fagundes, Maçada e Sato (1999, p. 17)

A partir do Quadro 1 é possível verificar que a Aprendizagem Baseada em Projetos está alinhada aos pressupostos indicados por Fagundes, Maçada e Sato (1999), podendo ainda ser caracterizado como abordagem de aprendizagem ativa. Também destaca-se como uma alternativa para se elaborar currículos e se adotar práticas inovadoras na educação.

Segundo Badia e García (2006) a introdução de recursos tecnológicos influencia de maneira positiva a metodologia ABP, facilitando a gestão, o acesso e a distribuição das informações e do conteúdo, permitindo que se estabeleça uma melhor interação entre os participantes. Sendo assim, ao implementar o uso de ferramentas digitais com o intuito de alcançar certas metas de aprendizagem, o professor é capaz de superar as limitações da sala de aula tradicional (BOSS; KRAUSS, 2007).

Ainda segundo Boss e Krauss (2007) as ferramentas digitais podem se fazer presentes durante a implementação de uma metodologia ABP de diferentes modos. Os benefícios do uso de ferramentas online podem incluir uma melhor organização dos processos de trabalho entre professores e alunos, e em maneiras mais eficientes de monitorar a maneira como os estudantes pensam (BRUSH; SAYE, 2002). O uso de diferentes recursos online também pode permitir a comunicação com elementos externos à sala de aula, facilitar o acesso a outros pontos de vista, gerenciar o trabalho em grupo e viabilizar a troca de feedbacks entre professores e alunos (CASTRO, 2016).

Alguns dos recursos online que apoiam a ABP incluem bibliotecas de projetos (RAVITZ; BLAZEVSKI, 2014), blogs dedicados ao tópico ${ }^{1}$ e ferramentas de avaliação e feedback ${ }^{2}$. Além disso, tais recursos criam um elo entre esta metodologia e o uso de ferramentas digitais (BRUSH; SAYE, 2002).

Ardaiz-Villanueva et al. (2011) constataram que o uso de ferramentas digitais na organização de projetos pode estimular a geração de ideias e promover a criatividade dos estudantes inseridos em uma dinâmica ABP. A pesquisa foi realizada com 34 estudantes de Engenharia de Computação integrando o uso das ferramentas wikideas e creativity connector às atividades dentro e fora de classe, permitindo que os alunos pudessem ter acesso às ideias

\footnotetext{
${ }^{1}$ www.edutopia.org

2 www.projectfoundry.com/ 
dos colegas, avaliando-as e definindo a aplicabilidade das mesmas. Por meio de questionários e dos dados coletados a partir das ferramentas os autores puderam concluir que o uso destes recursos contribui de maneira positiva e significativa na criação de ideias originais.

Seet e Quek (2010) utilizaram uma interface de comunicação sincrônica mediada por computadores para permitir que alunos de diferentes países trabalhassem no mesmo projeto. Neste estudo, os educandos foram apresentados a uma metodologia que mesclava o ensino presencial e à distância. Ou seja, além da colaboração entre os colegas de grupo presentes na sala de aula, os estudantes participaram de discussões com alunos de uma escola de outro país. O estudo apontou que o apoio do professor é crucial nas interações online, nas discussões entre os discentes e nas relações de parceria entre estes e outros alunos.

Barak e Dori (2004) utilizaram um ambiente informatizado como suporte à ABP, em aulas de Química dos anos iniciais do Ensino Superior. Os alunos utilizaram programas de computador para escrever as fórmulas moleculares e criar representações tridimensionais de compostos químicos, os quais deveriam ser posteriormente analisados pelos mesmos. Depois de classificar quimicamente a substância, os alunos deveriam resolver um problema baseado nos usos e aplicações deste elemento. Os pesquisadores chegaram à conclusão de que a introdução de uma metodologia ABP com o suporte da informática ajudou os alunos a melhorarem seu entendimento de conceitos químicos, teorias e estruturas moleculares.

Outro exemplo bem sucedido da utilização de recursos digitais para o enriquecimento de uma ABP pode ser encontrado no trabalho de Castro e Castro Filho (2015). Neste artigo os autores desenvolveram um trabalho no qual os alunos assumiram um papel mais ativo na construção do conhecimento, manipulando dados e construindo gráficos com o uso de laptops fornecidos pela escola. Os resultados das investigações do grupo foram postados em um blog onde os estudantes compartilhavam suas descobertas, estimulando o engajamento e contribuindo na apreensão de novos significados. Além das metodologias já citadas, o uso das Tecnologias Digitais da Informação e Comunicação (TDIC) se mostra como uma possível ferramenta de engajamento e de construção de conhecimento. Para Miskulin et al. (2006) a informática contribui para a democratização das dinâmicas entre professores e alunos, conferindo um caráter colaborativo à aprendizagem.

As tecnologias e as novas mídias digitais possibilitam ao homem se expressar de maneiras diversas, se utilizando de formas de comunicação tais como sons, imagens, gráficos e textos (NUNES, 2012). Além disso, no contexto de uma sociedade que faz cada vez mais uso da tecnologia para a criação e troca de novas informações, Ponte, Oliveira e Varanda 
(2003) acreditam que o processo de ensino e de aprendizagem de Matemática está fundamentalmente ligado ao uso das TDIC.

Para Papert (2008) a utilização do computador no ambiente de ensino pode ocorrer segundo duas abordagens: a instrucionista, na qual apesar da utilização de tecnologias o ensino permanece restringido às práticas tradicionais, e a construtivista, na qual as dinâmicas permitem que o aprendizado seja atingido enquanto o aluno atua de forma ativa na construção do conhecimento.

Dessa forma, cabe ao professor elaborar situações onde a utilização destes recursos esteja integrada a práticas pedagógicas adequadas, a fim de não perpetuar o senso comum de que inserir ferramentas tecnológicas em sala implica, por si só, em uma evolução no aprendizado dos alunos.

\section{Procedimentos metodológicos}

Esta pesquisa é caracterizada como qualitativa, pois enfatiza as ações e as experiências escolares. Com o intuito de atingir os objetivos de [1] apresentar projetos colaborativos e interdisciplinares realizados no âmbito da Educação Básica; e [2] analisar as contribuições das tecnologias digitais na aprendizagem baseada em projetos; foi realizada uma pesquisa descritiva e explicativa com projetos de aprendizagem realizados em duas escolas públicas municipais, localizadas na cidade de Fortaleza, no estado do Ceará. Os dois projetos analisados duraram cerca de 3 meses e utilizaram, ao longo de sua realização, laptops educacionais, livros didáticos adotados pela escola, recursos digitais e blogs.

Os dados analisados foram coletados por meio de observações realizadas durante as aulas de Matemática (diários de campo); gravações de áudios (entrevistas não estruturadas), gravações de vídeos e materiais produzidos ao longo dos projetos. Os critérios para a eleição dos instrumentos de coletas de dados foram determinados de acordo com o objetivo a ser alcançado. Desta forma, elegeu-se como técnicas de coletas de dados a observação e a análise de conteúdo, uma técnica que permite a descrição sistemática, objetiva e qualitativa do conteúdo da comunicação (LAKATOS; MARCONI, 2007).

Os resultados serão apresentados nas duas próximas seções: a primeira, em que os projetos de aprendizagem serão descritos; e a segunda, em que se apresentará uma análise das contribuições das tecnologias digitais utilizadas ao longo dos projetos apresentados. 


\section{Projetos colaborativos e interdisciplinares}

A interdisciplinaridade possibilita o diálogo, o reencontro e a cooperação entre diferentes disciplinas. Nesse sentido, essa relação pode ir desde a simples comunicação até a integração recíproca dos conceitos fundamentais e da teoria do conhecimento. Pode ainda ser vista como a integração e o empenho de educadores em um trabalho que promova a sinergia entre as disciplinas escolares e a realidade dos estudantes (LÜCK, 1995). É uma prática que objetiva uma formação global dos alunos, permitindo que os mesmos possam enfrentar os problemas do mundo real, exercendo a sua cidadania.

Para Seabra e Passos (2015), ao implementarem um projeto colaborativo e interdisciplinar, destacam que esta prática contribui para um aprendizado crítico, uma vez que incentiva a formação colaborativa do conhecimento, além de ter influência na geração de valores culturais dos alunos. Sendo assim, a ABP se mostra como uma metodologia com potencial para promover a autonomia dos alunos em um ambiente interdisciplinar. $\mathrm{Na}$ sequência apresentar-se-á projetos de aprendizagem colaborativos e interdisciplinares.

\subsection{Projeto Um Mundo de Informações}

O projeto teve a participação direta dos 26 estudantes do $5^{\circ}$ ano do Ensino Fundamental, do turno da manhã, de uma Escola Municipal de Fortaleza - Ceará, além da participação indireta de todo o corpo docente, discente e comunidade escolar. Dentre os objetivos deste projeto, destaca-se o desenvolvimento da aprendizagem de conceitos relacionados ao tratamento da informação, bloco pertencente ao currículo da Matemática, como construção e interpretação de gráficos de barras e de setores, a partir da vivência de um processo investigativo, mediante a integração das tecnologias digitais ao currículo escolar (CASTRO; CASTRO-FILHO, 2012).

Este processo investigativo era composto de quatro etapas: planejamento, coleta dos dados, organização dos dados e publicação da notícia no $b \log ^{3}$, conforme esquema apresentado na figura 1 .

\footnotetext{
${ }^{3}$ http://1mundodeinformacoes.blogspot.com.br/search/label/Escola\%20Monteiro\%20Lobato 
Figura 1: Etapas do processo investigativo - Projeto Um Mundo de Informações
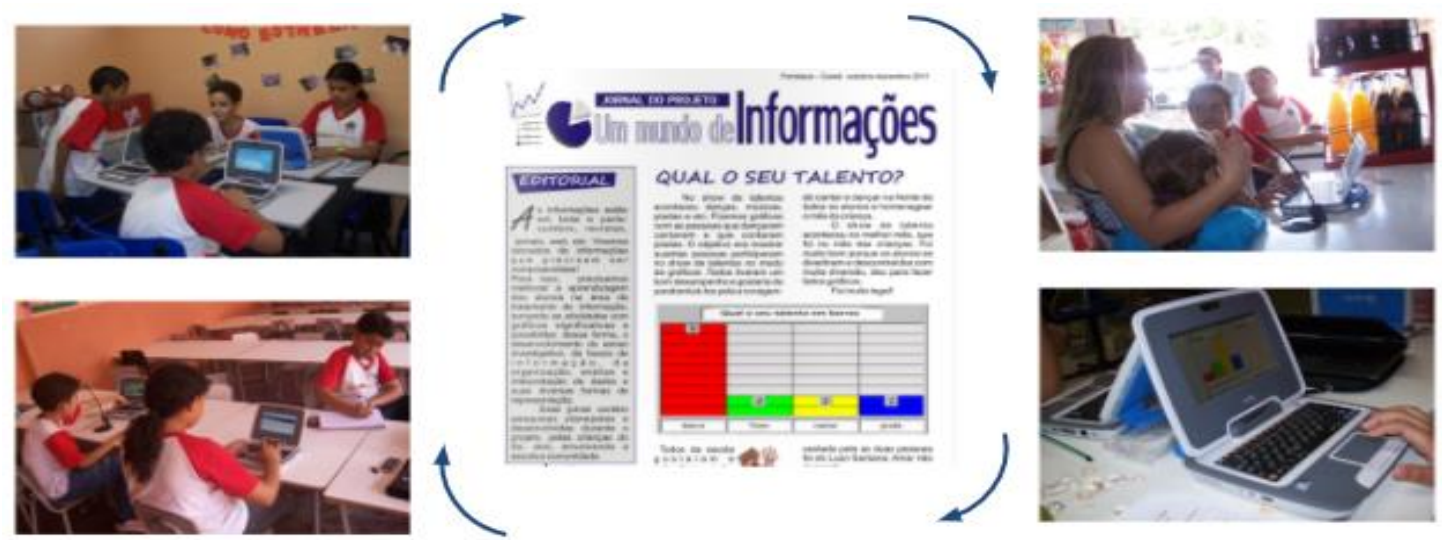

Fonte: (dos autores, 2018)

A Figura 1 evidência momentos vivenciados por alguns grupos, dentro e fora da sala de aula e da escola, durante a construção de notícias que geraram um jornal digital ${ }^{4}$.

A etapa de planejamento dava início ao processo de investigação. Neste momento os estudantes se dividiram conforme interesse por temas e/ou afinidades, respondendo aos seguintes questionamentos: O que pesquisar? Por que pesquisar? Como pesquisar? Com quem pesquisar? A divisão das equipes, a escolha do tema e às respostas a esses questionamentos geraram conflitos e em alguns casos desconfiança, já que os estudantes não vivenciam cotidianamente essa liberdade de escolha.

Ao responderem a estas perguntas, os grupos passavam para a etapa seguinte, ou seja, para a coleta dos dados: momento em que era iniciada a investigação junto ao público definido no planejamento. A coleta dos dados aconteceu de diversas formas (entrevistas, perguntas) e com diferentes instrumentos (editor de texto, tabela, recurso digital), tendo evoluído à medida que o processo era compreendido. Após a coleta de dados, iniciava-se a organização de dados.

A etapa de organização de dados contemplou a escolha da representação mais adequada (gráfico de barras ou de setores) e, em alguns casos, o cruzamento de categorias para a interpretação dos resultados obtidos, tendo sido influenciada a partir da forma como a coleta de dados era realizada.

Por fim, a etapa de publicação da notícia consistiu na sistematização de todo o trabalho investigativo realizado nas etapas anteriores. Em grupo, os estudantes pesquisaram,

\footnotetext{
${ }^{4}$ http://issuu.com/pedrotaraujo/docs/uca/6?e=0 


\section{\#tear}

quando necessário, sobre os assuntos que seriam escritos, além de buscar imagens e construir gráfico que tinham relação com a notícia, as quais seriam utilizadas para a ilustração do texto que estavam construindo. No decorrer do processo os estudantes receberam orientações sobre a estrutura do gênero textual notícia (jornal), requisitando a criação de uma manchete, que deveria estar diretamente relacionada com a investigação realizada.

Ressalta-se que o processo de investigação vivenciado neste projeto permitiu que os estudantes fossem além do desenvolvimento da compreensão das relações matemáticas presente nos gráficos, pois ao experienciar cada uma das etapas, os alunos puderam entender e aprimorar noções de coleta de dados, de classificação, de escolha da amostra, de cruzamento de variáveis e da escolha do gráfico mais adequado para cada situação, a partir da reflexão, de discussões e análise das reportagens que foram definidas a partir do interesse dos grupos (CASTRO; CASTRO-FILHO, 2015). Dentre os resultados obtidos o projeto proporcionou a combinação de diferentes linguagens e tecnologias, de modo a integrar o currículo escolar, favorecendo a apropriação tecnológica e a formação cidadã (CASTRO, CASTRO-FILHO, 2012).

\subsection{Projeto Pensar, Conectar e Fazer}

Este projeto foi realizado com 12 estudantes de uma turma do $6^{\circ}$ ano do Ensino Fundamental de uma Escola de Tempo Integral do Município de Fortaleza - Ceará, tendo duração de 18 encontros, divididos em dois momentos: (1) Construção e reflexão de conceitos Matemáticos, com 12 encontros e (2) Produção colaborativa de vídeo a partir dos conceitos trabalhados nas aulas de Matemática, com 6 encontros. A realização do projeto separado em dois momentos foi necessária para adequar as atividades planejadas e realizadas pelos estudantes com a dinâmica escolar, já que, por acontecer em escola de Tempo Integral, não seria possível utilizar contraturno para fazer alguma atividade. Contudo, embora existisse essa separação, os conceitos matemáticos e a metodologia utilizada em ambos os momentos eram semelhantes.

Foram realizadas atividades, algumas dessas, utilizando o livro didático adotado pela escola, com suporte de ferramentas como o Cacoo, o Google Docs, o software Geogebra e o Recurso digital Equilibrando proporções ${ }^{5}$, por meio de laptops educacionais. Também foi proposta a criação e a análise de situações reais, as quais foram apresentadas e discutidas no

\footnotetext{
${ }^{5}$ http://www.projetos.unijui.edu.br/formacao/_medio/Matematica/EquilibrandoProporcoes/index.html 


\section{\#tear}

Whatsapp e postadas em blog $^{6}$.

As aulas de matemática tinham como objetivo proporcionar a construção dos conceitos a partir da produção de vídeos, servindo como importante momento de reflexão. Para orientar os estudantes foi criado um roteiro de seis etapas.

A primeira etapa envolvia a escolha do tema e trazia questionamentos como: Sobre o que será o vídeo? Por quê? O estudante tinha liberdade de escolher a temática que gostaria de abordar, no entanto, deveria contemplar os conceitos matemáticos presentes nas estruturas multiplicativas $^{7}$.

A segunda etapa consistia na realização da pesquisa. Para isso, os estudantes precisavam esclarecer: Como a matemática está relacionada com esse tema? Há relações de proporção ou proporcionalidade? O que o grupo sabe sobre esse assunto? As pesquisas foram realizadas utilizando diferentes fontes, como: internet, entrevistas, livros, filmagens, registros fotográficos, visitas a locais, vídeos, dentre outros.

A terceira etapa contemplou a elaboração do roteiro do vídeo. Para isso, os estudantes foram orientados a definirem o tipo de recurso que pretendiam utilizar: vídeos remixados a partir de filmes, filmagens com pessoas, cenas montadas com imagens, animações quadro-aquadro, Stop Motion, dentre outros. Além disso, deveriam estabelecer: a organização do recurso (filmagens com pessoas ou com massinhas e outros materiais); a divisão de tarefas (quem cuidaria da direção, da sonoplastia, das imagens); cada elemento da cena.

$\mathrm{Na}$ quarta etapa os estudantes cuidaram da execução do roteiro construído na etapa anterior. Na quinta etapa os estudantes fizeram, quando necessário, a edição do vídeo, e o compartilhamento do material produzido via Whatsapp, Youtube e/ou blog.

Por fim, na sexta etapa os estudantes realizaram a avaliação do vídeo produzido e do processo, respondendo aos seguintes questionamentos: O que aprendi ao elaborar esse vídeo? Como foi a integração do grupo? O objetivo proposto, inicialmente, foi alcançado? As relações matemáticas apresentadas estão claras? Durante a produção do vídeo surgiram outras questões?

Ao final, foram produzidos três vídeos: A grande corrida ${ }^{8}$ - vídeo inspirado na fábula "a tartaruga e a lebre", em que é narrada a história de uma corrida, feita por dois colegas, de

\footnotetext{
${ }^{6}$ http://pensar-conectar-fazer.blogspot.com.br/

${ }^{7}$ O Campo Conceitual das Estruturas Multiplicativas envolve os conceitos de funções linear e não-linear, o espaço vetorial, a análise dimensional, a fração, a razão, a proporção, o número racional, a multiplicação, a divisão, dentre outros.

${ }^{8} \mathrm{https}: / /$ www.youtube.com/watch?v=dlLbL0A-O8Y
} 
casa à escola, mostrando graficamente essa evolução; Doçura economizada ${ }^{9}$ - Vídeo em que um grupo de estudantes encenam uma compra feita numa loja de doces, mostrando graficamente a melhor opção de compra a ser feita; Tenha consciência, coma bem! ${ }^{10}$ - Vídeo que retrata algumas reflexões a respeito da alimentação, por meio de tabelas e de gráficos, relacionando a massa dos alimentos e a quantidade de gordura.

A análise do processo vivenciado pelos estudantes, ao longo do projeto, demonstra o crescimento cognitivo, tanto no aspecto conceitual, procedimental, como atitudinal, pois, além do domínio e precisão na abordagem dos conceitos matemáticos nos vídeos, os estudantes se apropriaram dos procedimentos necessários em cada etapa, como também, desenvolveram a autonomia, o poder de argumentação, o senso crítico, a criatividade, o que condiz com a construção e produção de conhecimento (CASTRO, 2016).

A seguir serão apresentados os resultados que emergiram das análises destes projetos de aprendizagem em relação às contribuições das tecnologias digitais.

\section{Contribuições das tecnologias digitais para o desenvolvimento de projetos}

Ao desenvolver um projeto interdisciplinar que possa contribuir para o aprendizado dos alunos, faz-se importante considerar quais ferramentas serão utilizadas durante o desenvolvimento e a aplicação do mesmo. Os projetos "Pensar, Conectar e Fazer" e "Um Mundo de Informações" fazem uso das TDIC para promover a criação de conteúdos pelos próprios alunos, permitindo que os mesmos se conectem de maneira significativa com os conhecimentos formais vistos em sala.

Segundo Kurubacak (2007) softwares educacionais e recursos digitais são ferramentas utilizadas em práticas pedagógicas que fazem uso da metodologia de projetos. O Projeto "Um Mundo de Informações" utilizou recursos digitais para produzir gráficos de barras e de setores ${ }^{11}$ permitindo que os estudantes se apropriassem das características de cada um destes gráficos ao manipular estes recursos para construir os respectivos gráficos. No Projeto "Pensar, Conectar e Fazer" o recurso Equilibrando Proporções foi manuseado para auxiliar no desenvolvimento das relações multiplicativas presentes em situações de proporção, assim como o software Geogebra auxiliou na construção de gráficos lineares para representar algumas destas relações. Sendo assim, o uso planejado de um recurso digital e/ou software pode levar o estudante a desenvolver seus modelos cognitivos, a analisar relações entre

\footnotetext{
${ }^{9} \mathrm{https} / / / \mathrm{www}$. youtube.com/watch?v=PIu4tWqjFDY

${ }^{10} \mathrm{https}: / /$ www.youtube.com/watch?v=RJ3ilqhNKyY

${ }^{11} \mathrm{http}: / / \mathrm{www}$.proativa.virtual.ufc.br/manipulatives/nav/manipulativos.html 
fenômenos e a melhorar seu raciocínio abstrato.

Basham (2011) relata suas experiências, realizadas no Canadá, com kits contendo diferentes conjuntos de ferramentas digitais a serem utilizadas na elaboração e execução de tarefas ligadas à ABP. Os kits foram criados de maneira a serem facilmente levados a campo, consistindo em materiais para coleta de dados e acesso à informação, assim como ferramentas digitais para a gestão das atividades e materiais instrucionais. Além do kit, os alunos que participaram dos experimentos receberam tarefas de acordo com sua faixa etária e estavam em séries que iam da Elementary School, até o ensino universitário. O autor chegou à conclusão de que ao mesclar a tecnologia à experiência instrucional o professor aumenta o envolvimento dos alunos e facilita que os mesmos expressem sua compreensão do assunto.

Para Pence (2007) a introdução de ferramentas móveis para fins educativos permite que os estudantes possam compartilhar seus conhecimentos, dúvidas e informações por meio de computadores ou smartphones. Verifica-se, nos dois projetos apresentados, que a mobilidade foi importante para ampliar o espaço e o tempo de sala de aula, proporcionar a discussão de situações reais e significativas para os estudantes.

Nesse contexto pode-se destacar ainda o uso de redes sociais, como o Whatsapp, possibilitando a formação de grupos onde é possível criar conteúdos e desenvolver discussões e materiais relacionados a projetos (MINSHEW; ANDERSON, 2015; CASTRO, 2016). O Whatsapp foi utilizado apenas no Projeto "Pensar, Conectar e Fazer", permitindo que os estudantes pudessem compartilhar o registro de situações relacionadas à matemática presente nas práticas cotidianas.

Para Hafner, Li e Miller (2015) o uso do Whatsapp possibilita a mediação entre o estudante que procura compreender determinado tópico e o colega mais capaz, permitindo a criação de um cenário onde a transmissão do conhecimento não está centralizada na figura do professor. No entanto, apesar de a maioria dos estudantes estarem familiarizados com o uso de recursos digitais, lhes faltam as habilidades necessárias para utilizar estas ferramentas de maneira produtiva, devendo o professor se posicionar como facilitador deste amadurecimento (VALLS-BARREDA, 2016).

O processo de produção de material digital, seja o jornal digital no Projeto "Um Mundo de Informações" ou os vídeos no caso do Projeto "Pensar, Conectar e Fazer", estimulou a discussão do conhecimento produzido. $\mathrm{O}$ uso desta ferramenta pode tornar o conteúdo significativo para os estudantes, contribuindo de maneira qualitativa na construção do conhecimento (ERSTAD, 2002). 


\section{\#tear}

O uso do blog como ferramenta durante a aprendizagem baseada em projetos pode levar os estudantes a aumentarem a independência de seu aprendizado (PINKMAN, 2005). Sun e Chang (2012) afirmam que a utilização do blog permite que os estudantes compartilhem o conhecimento de maneira ativa e reflexiva, contribuindo para a melhora de suas habilidades em escrita. Retnawati (2017) admite que ao fazer uso do blog durante a ABP o aluno pode desenvolver sua capacidade de gerenciar o próprio aprendizado, além de melhorar suas habilidades de comunicação. Isso ficou evidenciado, principalmente, no Projeto "Um Mundo de Informações", pois os estudantes faziam as notícias, mesmo fora do horário de aula, buscando registrar diferentes situações que aconteciam no contexto escolar e na comunidade. Já no Projeto "Pensar, Conectar e Fazer" o blog foi utilizado com menor frequência, sendo usado, preferencialmente, para registrar acontecimentos do projeto.

Sendo assim, é possível crer que a implementação de uma metodologia ABP pode se beneficiar sobremaneira com a adoção de ferramentas digitais. A utilização das mesmas permite que professor e aluno façam uso das potencialidades da metodologia de projetos, ajudando a superar as barreiras impostas pela sala de aula tradicional.

\section{Considerações Finais}

Este artigo teve como objetivos apresentar projetos de aprendizagem realizados no âmbito da Educação Básica e analisar as contribuições das tecnologias digitais na aprendizagem baseada em projetos. Foi apresentado o Projeto "Um Mundo de Informações" que buscou desenvolver a compreensão de gráficos e o tratamento da informação, a partir de um processo investigativo em que os estudantes definiram os temas e todas as etapas do processo, produzindo, ao final, um jornal digital. Também foi retratado o Projeto "Pensar, Conectar e Fazer" que tinha, dentre os objetivos, o desenvolvimento da compreensão de conceitos presentes nas estruturas multiplicativas que foram contextualizados, pelos estudantes que participaram do projeto, por meio da construção de vídeos.

Ao analisar a influência das tecnologias digitais para o desenvolvimento de uma intervenção pedagógica voltada para a Aprendizagem Baseada em Projetos, é possível notar que a utilização das TDIC traz uma gama de novas possibilidades à prática escolar. Ao permitir que o aprendizado não esteja restrito apenas ao que é feito em sala de aula, com recursos que possibilitem aos alunos estarem conectados entre si e com o professor, torna-se possível a integração do conhecimento formal ao cotidiano do aprendiz. 
Um dos fatores que diferenciam a ABP de outras metodologias ativas é a criação de um produto concreto que represente os novos conhecimentos adquiridos pelos alunos, bem como suas atitudes com relação à questão investigada. O produto gerado como resultado destas dinâmicas é muitas vezes apresentado em forma de vídeos, fotografias, desenhos, relatórios ou como um conjunto de artefatos complementares.

Como visto nos artigos aqui expostos, pode-se então destacar o caráter facilitador desempenhado pelas TDIC na criação de conteúdos em ABP. A internet fornece softwares e aplicativos gratuitos que podem ser utilizados tanto para a elaboração de conteúdo, como no auxílio da visualização de conceitos ou na coleta e análise de dados.

O uso do aplicativo Whatsapp ofereceu aos alunos novas possibilidades de interação social, promovendo um meio de cooperação e colaboração online. Além disso, ao documentar e publicar as etapas do processo de elaboração dos projetos aqui abordados em um blog, criou-se uma representação duradoura das etapas do processo de aprendizado.

O uso de recursos digitais, bem como do software Geogebra, proporcionou aos alunos uma chance de interagir de maneira ativa com os conceitos matemáticos. O uso destes recursos digitais oportunizou a possibilidade de uma visualização mais ampla dos conceitos, ajudando a tornar os resultados de suas investigações em gráficos. Dentre eles destacam-se a ampliação do tempo e espaço; a possibilidade de trabalhar com dados e informações reais; a viabilidade de trabalhar com simulações; construir gráficos com maior rapidez e precisão, dentre outros. Dessa forma é possível concluir que o uso das TDIC, ainda que não constitua uma necessidade para a implementação de uma metodologia $\mathrm{ABP}$, trás muitos benefícios e possibilidades à mesma.

A interdisciplinaridade presente nesta prática pedagógica permite que os estudantes possam ter a noção de que o conhecimento não é algo limitado ou fragmentado, à maneira como se apresenta no currículo tradicional, integrando disciplinas para a solução de problemas reais. Durante a pesquisa para compor o estado da arte deste artigo foram encontrados poucos trabalhos abordando o papel das ferramentas digitais na criação de artefatos, visualização de conceitos ou na divulgação dos materiais criados por conta da atividade. Dessa forma, abre-se espaço para que futuras pesquisas nesta área possam abordar as possibilidades de criação conteúdo trazidas pelas TDIC. 


\section{PROJECT-BASED LEARNING: CONTRIBUTIONS OF DIGITAL TECHNOLOGIES}

Abstract: The insertion of technological resources in the classroom brings new possibilities and challenges to a pedagogical practice. However, there is a need for planning that addresses the new tools, allowing teachers and participants to take advantage of them. Thus, this work is projected in Project-Based Learning (ABP) in a municipal school in Fortaleza, as well as data from digital technologies in this type of methodology. To this end, the "Um Mundo de Informações" and "Pensar, Conectar e Fazer" projects, carried out, respectively, in the 5th and 6th grades of Elementary School are detailed. In addition, it is performed an evaluation of the digital tools used in these activities. It was concluded that the use of the tools influenced in a positive way in the application of the projects, besides allowing an integration of knowledge at an interdisciplinary level and in the generation of educational products.

Keywords: Project-based learning. Digital technologies. Active Methodology. Interdisciplinarity.

\section{Referências}

ARDAIZ-VILLANUEVA, O. et al. Evaluation of computer tools for idea generation and team formation in project-based learning. Computers \& Education, [s.1.], v. 56, n. 3, p.700711, abr. 2011. Elsevier BV. Disponível em:

<http://dx.doi.org/10.1016/j.compedu.2010.10.012>. Acesso em: 10 mar. 2018.

BADIA, A.; GARCÍA, C. Incorporación de las TIC en la enseñanza y el aprendizaje basados en la elaboración colaborativa de proyectos. Revista de Universidad y Sociedad del

Conocimiento, v. 3, n. 2, p. 42-54, 2006.

BARAK, M.; DORI, Y. J. Enhancing undergraduate students' chemistry understanding through project-based learning in an IT environment. Science Education, [s.l.], v. 89, n. 1, p.117-139, 2004. Disponível em : <http://dx.doi.org/10.1002/sce.20027>. Acesso em: 10 mar. 2018.

BASHAM, James. It's in the Bag: Digital Backpacks for Project-Based Learning. Learning And Leading With Technology, [s. I.], v. 39, n. 2, p.24-27, 2011.

BATISTA, S. C. F. Softmat: um repositório de softwares para matemática do Ensino Médio um instrumento em prol de posturas mais conscientes na seleção de softwares educacionais. 2004. 202 f. Dissertação (Mestrado em Ciências da Engenharia)- Universidade do Norte Fluminense, Campos dos Goytacazes, 2004.

BOSS, S.; KRAUSS, J. Reinventing Project Based Learning: Your Field Guide to RealWorld Projects in the Digital Age. Washington: International Society For Technology In Education, 2007. 200 p.

BOSS, S.; LARMER, J.; MERGENDOLLER, J. R.; PBL for 21ST Century Success. Buck Institute for Education (BIE), 2013. 148 p. 
BUCKINGHAM, D. Beyond technology: rethinking learning in the age of digital culture. Em J. Pettersen (Org.), Youth Media Democracy: Perceptions of New Literacies (pp. 43-57). Dublin: Centre for Social \& Educational Research, 2009.

CASTRO, J. B. A utilização de objetos de aprendizagem para a construção e compreensão de gráficos estatísticos. Dissertação (Mestrado em Educação Universidade Federal do Ceará), 2012.

CASTRO, J. B. Construção do conceito de covariação por estudantes do Ensino Fundamental em ambientes de múltiplas representações com suporte das tecnologias digitais. Tese (Doutorado em Educação) - Universidade Federal do Ceará, Fortaleza, 2016.

CASTRO, J. B.; CASTRO-FILHO, J. A. Desenvolvimento do pensamento estatístico com suporte computacional. Educ. Matem. Pesq., 17(5), 870-896, 2015.

CASTRO, J. B.; CASTRO-FILHO, J. A. Projeto Um Mundo de Informações: Integração de Tecnologias Digitais ao Currículo Escolar. I Congresso Brasileiro de Informática na Educação. Rio de Janeiro: Workshop sobre formação e experiências educacionais no programa Um Computador por Aluno - I CBIE. 2012. p. 1-10.

ERSTAD, O. Norwegian students using digital artifacts in project-based learning. Journal Of Computer Assisted Learning, [s.1.], v. 18, n. 4, p.427-437, 11 dez. 2002.

FAGUNDES, L. C.; SATO, L. S.; MAÇADA, D. L. Aprendizes do futuro: as inovações começaram!. Brasília: MEC. 1999. Disponível em:

<http://pa2009b2.pbworks.com/f/aprender.pdf>. Acesso em: 10 mar. 2018.

GRECA, I. M., MOREIRA, M. A. Mental, Physical, and Mathematical Models in the Teaching and Learning of Physics. Science Education, V. 86 (1) 106-121, 2001.

HAFNER, C. A.; LI, D. C.; MILLER, L. Language Choice Among Peers in Project-Based Learning: A Hong Kong Case Study of English Language Learners' Plurilingual Practices in Out-of-Class Computer-Mediated Communication. Canadian Modern Language Review, [s.1.], v. 71, n. 4, p.441-470, nov. 2015. University of Toronto Press Inc. (UTPress). Disponível em: <http://dx.doi.org/10.3138/cmlr.2712〉. Acesso em: 10 mar. 2018.

HANSEN, A. O. ; DEFFACCI, F. A.. Inserção das tecnologias de informação e comunicação no processo de ensino e de aprendizagem: Uma análise documental na EMEF "José Benigo Gomes”. Interfaces da Educação, Paranaíba, v. 6, n. 17, p.263-288, 2015.

KARAHOCA, D.; KARAHOCA, A.; UZUNBOYLUB, H. Robotics teaching in primary school education by project based learning for supporting science and technology courses. Procedia Computer Science, [s.1.], v. 3, p.1425-1431, 2011. Elsevier BV.

KURUBACAK, G. Building knowledge networks through project-based online learning: A study of developing critical thinking skills via reusable learning objects. Computers In Human Behavior, [s.1.], v. 23, n. 6, p.2668-2695, nov. 2007. Elsevier BV. Disponível em: <http://dx.doi.org/10.1016/j.chb.2006.08.003>. Acesso em: 10 mar. 2018. 
LAFFEY, J. et al. A computer-mediated support system for project-based learning. Educational Technology Research And Development, [s.1.], v. 46, n. 1, p.73-86, mar. 1998. Springer Nature. Disponível em: <http://dx.doi.org/10.1007/bf02299830>. Acesso em: 10 mar. 2018.

LAKATOS, E. M.; MARCONI, M. de A. Fundamentos de metodologia científica. 6. ed. 5. reimp. São Paulo: Atlas, 2007.

LAROCCA, C.; MARGOTTINI, M.; CAPOBIANCO, R. Collaborative Learning in Higher Education. Open Journal Of Social Sciences, [s.1.], v. 02, n. 02, p.61-66, 2014. Scientific Research Publishing, Inc, Disponível em: <http://dx.doi.org/10.4236/jss.2014.22009>. Acesso em: 10 mar. 2018.

LÜCK, H. Pedagogia interdisciplinar: fundamentos teórico-metodológicos. Petrópolis: Vozes, 1995. $92 \mathrm{p}$.

MENEZES, H. C.; FARIA, A. G. F. Utilizando o monitoramento ambiental para o ensino da química. Pedagogia de Projeto. Química nova, 26(2), pp. 287-290, 2003.

MINSHEW, L.; ANDERSON, J. Teacher Efficacy in 1:I iPad Integration in Middle School Science and Math Classrooms. Contemporary Issues in Technology and Teacher Education, 15(3), 334-367, (2015). Association for the Advancement of Computing in Education (AACE).

MISKULIN, R. G. S.; PEREZ, G.; SILVA, M. R. C.; MONTREZOR, C. L.; SANTOS, C. R.; TOON, E.; FILHO, P. A. L.; SANTANA, P. H. O. Identificação e Análise das Dimensões que Permeiam a Utilização das Tecnologias de Informação e Comunicação nas Aulas de Matemática no Contexto da Formação de Professores. Bolema: Mathematics Education Bulletin= Bolema: Boletim de Educação Matemática, v. 19, n. 26, 2006.

MORAN, J. M.; MASETTO, M.; BEHRENS, M. Novas tecnologias e mediação pedagógica. 12. ed. São Paulo: Papirus, 2006.

NOGUEIRA, N. R. Pedagogia dos projetos: etapas, papéis e atores. São Paulo: Érica, 2009.

NUNES, Rosemeri Coelho. Mídias aplicadas na educação e AVEA / Rosemeri Coelho Nunes. - Florianópolis: Publicações do IF-SC, 2012.

PAPERT, S. A máquina das crianças: repensando a escola na era da informática. Porto Alegre: Artes Médicas, 2008.

PENCE, H. E. Preparing for the real Web generation. Journal of Educational Technology Systems, 35(3), 347-356, 2007.

PINKMAN, K. Using Blogs in the Foreign Language Classroom: Encouraging Learner Independence. The JALT CALL Journal. 1(1), 12-24, 2005.

PONTE, J. P.; OLIVEIRA, H.; VARANDAS, J. M. O contributo das tecnologias de informação e comunicação para o desenvolvimento do conhecimento e da identidade profissional. In: FIORENTINI, D. (Org). Formação de professores de Matemática. 
Campinas, SP: Mercado Letras, 2003.

PRINCE, M. Does Active Learning Work? A Review of the Research. Journal Of Engineering Education, [s.1.], v. 93, n. 3, p.223-231, jul. 2004. Wiley-Blackwell. Disponível em: 〈http://dx.doi.org/10.1002/j.2168-9830.2004.tb00809.x>. Acesso em: 10 mar. 2018.

RAVITZ, J.; BLAZEVSKI, J. Assessing the Role of Online Technologies in Project-based Learning. Interdisciplinary Journal Of Problem-based Learning, [s.1.], v. 8, n. 1, p.65-79, 10 abr. 2014. Purdue University (bepress). http://dx.doi.org/10.7771/1541-5015.1410.

RENNINGER, K. A.; SHUMAR, W. Building virtual communities. New York: Cambridge University Press, 2002. 416 p. (Learning in Doing: Social, Cognitive and Computational Perspectives).

RETNAWATI, H. Improvement The Acquisition of Research Methodology and Self Regulated Learning through Blog Project. Jurnal Cakrawala Pendidikan, [s.1.], v. 36, n. 2, p.180-192, 30 jun. 2017. Universitas Negeri Yogyakarta. Disponível em: <http://dx.doi.org/10.21831/cp.v36i2.10911>. Acesso em: 10 mar. 2018.

SAHIN, I.; THOMPSON, A. Using Rogers's theory to interpret instructional computer use by COE faculty. Journal of Research on Technology in Education, 39 (1), 81-104, 2006.

SEABRA, L.; PASSOS, R. Uma Experimentação Colaborativa e Interdisciplinar em Escolas Públicas de Goiás. Revista Ufg, Goiânia, v. 15, n. 16, p.61-76, jun. 2015. Semestral. Disponível em: <https://www.proec.ufg.br/up/694/o/04_16.pdf>. Acesso em: 10 mar. 2018.

SEET, Ling Ying Britta; QUEK, Choon Lang. Evaluating students' perceptions and attitudes toward computer-mediated project-based learning environment: A case study. Learning Environments Research, [s.1.], v. 13, n. 2, p.173-185, 6 jun. 2010. Springer Nature.

Disponível em: <http://dx.doi.org/10.1007/s10984-010-9073-8>. Acesso em: 10 mar. 2018.

SUN, Y,C.; CHANG, Y. J. Blogging to Learn: Becoming EFL Academic Writers through Collaborative Dialogues. Language Learning \& Technology, Volume 16, Number 1 pp. 43 61, 2012.

TATTO, F.; SCAPIN, I. J. Matemática: Por que o Nível Elevado de Rejeição? Revista de Ciências Humanas, v. 5, n. 5, p. 57-70, 2004.

VALLS-BARREDA, S. Analysis of project based learning in a digital environment at a networked high school. Journal For Educators, Teachers And Trainers, [Granada], v. 7, n. 1, p.27-49, 2016. 